\title{
Helicobacter pylori babA2 Positivity Predicts Risk of Gastric Cancer in Ardabil, a Very High-Risk Area in Iran
}

\author{
Esmat Abdi $^{1}$, Saeid Latifi-Navid ${ }^{1 *}$, Abbas Yazdanbod ${ }^{2}$, Saber Zahri ${ }^{1}$
}

\begin{abstract}
Background: Ardabil, a Northwestern province of Iran, was found to have the highest rate of gastric cancer (GC) in the country (ASRs $=51.8 / 100,000$ for males and 24.9/100,000 for females) and one of the highest gastric cardia cancer rates in the world. The aim of the present study was to assess the associations of the cagA and babA2 status of Helicobacter pylori with GC in the Ardabil population. Materials and Methods: A total of 103 patients with non-atrophic gastritis (56) and GC (47), who underwent endoscopy at the Imam Khomeini Hospital in Ardabil, were assessed. The status of $16 \mathrm{~S} \mathrm{rDNA}$, cagA and $\boldsymbol{b a b A 2}$ genes was determined using PCR and histopathological assessment was performed. Results: The following genotypic frequency was observed: $c a g A+(50.6 \%), c a g A-(49.4 \%), b a b A 2+(26.5 \%), b a b A 2-(73.5 \%) c a g A+/ b a b A 2+(19.3 \%), c a g A-/ b a b A 2+(7.2 \%)$, $c a g A+/ b a b A 2-(31.3 \%), c a g A-/ b a b A 2-(42.2 \%)$. Although the frequency of the $c a g A+, c a g A+/ b a b A 2+$ and $c a g A-/$ $b a b A 2+$ genotypes in patients with GC $(55.6 \%, 25.9 \%$, and $14.8 \%$, respectively) was higher than in those with NAG $(48.2 \%, 16.1 \%$, and 3.6\%, respectively), the difference did not reach significance. In contrast, the presence of the $b a b A 2$ gene $(40.7 \%$ vs $19.6 \%$ ) significantly increased the risk of GC; the age-sex-adjusted odds ratio (95\% confidence interval) was $5.068(1.506-17.058 ; P=0.009)$, by multiple logistic regression. Conclusions: It is proposed that the $\mathrm{H}$. pylori babA2 positivity might be considered as an important determinant of GC risk in Ardabil.
\end{abstract}

Keywords: H. pylori - cagA - babA2 - gastric cancer - high-incidence - Ardabil - Iran

Asian Pac J Cancer Prev, 17 (2), 733-738

\section{Introduction}

Helicobacter pylori is a microaerophilic gram negative spiral bacterium that is able to localize in the stomach mucosa for at least tens of thousands of year. Several epidemiological studies have shown that the $H$. pylori infection causes a variety of gastrointestinal symptoms such as chronic gastritis and adenocarcinoma (Suerbaum and Michetti, 2002). Although the incidence and mortality of gastric cancer (GC) have declined in recent decades, it is the third-ranking cause of cancer which leads to death and the fifth most common malignant disease in the world (Ferlay et al., 2015). Histologically, GC divided into the intestinal- and the diffuse-type carcinomas. Previous studies have suggested that the interaction between host and environmental factors are jointly responsible for development of GC (Leung et al., 2006).

Stomach cancer is very common in Iran (Alireza et al., 2005a; Alireza et al., 2005b). Ardabil, a volcanic and mountainous land in Northwestern province of Iran that is located in Caspian Sea littoral, includes the highest rate of GC within the country (ASR of 51.8/100,000 in men and 24.9/100,000 in women) (Sadjadi et al., 2003; Babaei et al., 2010). In this area, more than one-third of the GC occurs in the cardia site of the stomach which constitutes only $5-10 \%$ of the entire stomach, and the incidence for cardia sub site was 26.4 and 8.6 for males and females, respectively (Derakhshan et al., 2004; Babaei et al., 2009). H. pylori infection has been measured as $89 \%$ and $69 \%$ in Ardabil province and Iran, respectively (Sadjadi et al., 2003; Malekzadeh et al., 2004; Nouraie et al., 2009). We have previously indicated that all the Iranian $H$. pylori strains, including those with Ardabil signature, represent the European ancestry, influenced by extensive genetic exchange with neighboring countries. However, they have well preserved ethnic and geographic signatures within the country (Latifi-Navid et al., 2010). Ardabil isolates showed approximately equal contribution from the two European ancestral sources, Ancestral Europe1 and Ancestral Europe2 (AE1 and AE2) that were found in purer form in Central Asia (AE1) and North East Africa (AE2).

$\operatorname{CagA}$ is one of the putative virulence factors of $H$. pylori, which is encoded by the cytotoxin-associated gene $\mathrm{A}(\operatorname{cag} A)$ that is located in the cag pathogenicity island (cag PAI) and directly translocated into host gastric epithelial cells by a type-IV secretion system (T4SS) after bacterial attachment (Mattar et al., 2007; Ohnishi et al., 2008). It promotes the tumorigenesis of GC by interfering with multiple signaling pathways (Yong et al., 2015).

${ }^{I}$ Department of Biology, Faculty of Sciences, ${ }^{2}$ Gastrointestinal Cancer Research Center, Ardabil University of Medical Sciences, Ardabil, Iran*For correspondence: slatifin@yahoo.com 
Approximately, the 50 to $60 \%$ of $H$.pylori strains harbor cagA (Abasiyanik et al., 2002; Basso et al., 2008), whose expression induces the production of IL-8 and mucosal inflammation in cultured gastric cells (Chang et al., 2015; Ferreira et al., 2015). Several studies have been reported that the individuals harboring cagA-positive strains suffer from a high risk for gastric mucosal atrophy and GC, compared to those with strains that lack the cag PAI (Sozzi et al., 2005; Tan et al., 2006). orf17 and particularly cagL, which are other genotypes of cag PAI, significantly increased the risk of peptic ulceration (PU), but not GC. No significant association was found between the cagH and cagG genotypes and the risk of both the PU and the GC (Raei et al., 2015). H. pylori strains may be classified into two types: type I and type II, based on possessing the cag PAI (Bagheri et al., 2013). The East Asian subtype of the $\operatorname{cag} A$ gene $(\mathrm{A}, \mathrm{B}, \mathrm{D})$ strongly linked to severe gastritis and $\mathrm{GC}$, in comparison with western subtype $(\mathrm{A}, \mathrm{B}, \mathrm{C})$ (Argent et al., 2008).

Another important virulence factor is babA2 (blood group antigen binding adhesion) that encoded by the babA2 gene. BabA is a 78-KDa outer membrane protein (OMP) that binds to lewis $b$ antigens and ABO antigen on the surfaces of gastric epithelial cells (Gerhard et al., 1999). Two babA allelic types identified (babA1 and babA2); however, only the $b a b A 2$ gene is functionally active. The presence of the 10-bp insertion is the cause of the difference between babA1 and babA2 (Ilver et al., 1998). Expression of the $b a b A 2$ gene has also been associated with the risk of GC (Lee et al., 2006).

Since the diagnosis of GC in the earlier stages of infection is difficult; therefore, eradication of the H.pylori infection might be the main way of cancer conservation. Therefore, it is necessary to determine which strains of H. pylori lead to GC. H. pylori-specific genotypes could determine the clinical consequences and contribute to understanding of the cause of high tendency for GC (Figueiredo et al., 2002; Peek et al., 2010). The aim of the present study was therefore to determine the H.pylori $\operatorname{cag} A$ and $b a b A 2$ status and their associations with GC in Ardabil population.

\section{Materials and Methods}

\section{Participants of the study}

From February 2012 to January 2014, a total number of
103 consecutive adult patients who underwent endoscopy at the Imam Khomeini Hospital in Ardabil, Northwestern Iran, participated in this study. All patients were born and grew up in the rural or urban areas of Ardabil province. Fresh gastric mucosal biopsy specimens were obtained from each patient and classified by endoscopic and histopathological examinations. The study population consisted of patients with none-atrophic gastritis (NAG) and GC. None of the patients had received none steroidal anti-inflammatory drugs or antibiotics within the previous three months, and all the participants signed a written informed consent.

\section{Histopathological assessment}

The biopsy samples were fixed in $10 \%$ formalin and embedded in paraffin, and were stained by hematoxylineosin, Alcian blue-periodic acid Shiff (pH 2.5) and Giemsa for light microscopy, and histopathological evaluations were also applied according to the updated Sydney classification system (Dixon et al., 1996).

\section{Diagnosis of H. pylori infection}

During endoscopy, of each patient four biopsies (two from the antrum and two from the corpus) were taken for histological examination and DNA extraction. The Biopsy specimens were frozen at $-80^{\circ} \mathrm{C}$ until processing. Detection of $H$. pylori was performed by using a specific primer set (HP1/HP2) of H. pylori $16 S$ rDNA, selected from some previous published works that produced the PCR fragments of 519-bp (Table 1).

\section{DNA extraction and genotyping of $H$. pylori}

DNA was extracted from the biopsy specimens by using Genomic DNA purification kit (DNGTM-Plus, CinnaGen Co., Iran) according to the manufacturer's recommendations, and stored at $-20^{\circ} \mathrm{C}$. After DNA extraction, polymerase chain reaction (PCR) was performed in a volume of $30 \mu \mathrm{L}$ reaction volume containing $50 \mathrm{ng}$ of genomic DNA, $3 \mu \mathrm{L}$ of $10 \mathrm{X}$ PCR buffer (CinnaGen, Iran), $1 \mathrm{mM} \mathrm{MgCl} 2,200 \mu \mathrm{M}$ of each dNTP(CinnaGen Co., Iran), $0.5 \mu \mathrm{M}$ of each specific primer and $2 \mathrm{U}$ of Taq DNA polymerase (CinnaGen Co., Iran). Amplification was also performed under the following conditions: for $\operatorname{cagA}: 35$ cycles of $40 \mathrm{sec}$ at $94^{\circ} \mathrm{C}, 1 \mathrm{~min}$ at $50^{\circ} \mathrm{C}$ (C-terminus), $55^{\circ} \mathrm{C}$ (middle region), or $56^{\circ} \mathrm{C}$ (N-terminus) and $1 \mathrm{~min}$ at $72^{\circ} \mathrm{C}$, and for babA2: 35 cycles

Table 1. Oligonucleotide Primers Used for PCR

\begin{tabular}{|c|c|c|c|c|c|c|}
\hline \multicolumn{2}{|l|}{ Genes } & \multirow[t]{3}{*}{ Primers } & \multirow{2}{*}{$\begin{array}{l}\text { Sequences }\left(5^{\prime} \rightarrow 3^{\prime}\right) \\
\text { GCAATCAGCGTCAGTAATGTTC }\end{array}$} & \multirow{2}{*}{$\begin{array}{r}\text { Size of PCR } \\
\text { products } \\
(\mathrm{bp})\end{array}$} & \multicolumn{2}{|c|}{$\begin{array}{c}\text { Optimized } \\
\text { annealing } \\
\text { temperature }\left({ }^{\circ} \mathrm{C}\right)\end{array}$} \\
\hline \multirow[t]{2}{*}{$16 S r D N$} & HP1 & & & & 56 & (Lu et al., 2002) \\
\hline & HP2 & & GCTAAGAGATCAGCCTATGTCC & & & \\
\hline \multirow[t]{6}{*}{$\operatorname{cag} A$} & N-terminus & $\operatorname{Cag} A / \mathrm{N}-\mathrm{F}$ & CCATTTTAAGCAACTCCATAAACC & 413 & 56 & (Bakhti et al., 2015) \\
\hline & & CagA/N-R & CTGCAAAAGATTGTTTGGCagA & & & \\
\hline & Middle region & $\operatorname{CagA} / \mathrm{M}-\mathrm{F}$ & GGCAATGGTGGTCCTGGAGCTAGGC & 243 & 55 & (Bakhti et al., 2015) \\
\hline & & $\operatorname{Cag} A / \mathrm{M}-\mathrm{R}$ & GGAAATCTTTAATCTCAGTTCGG & & & \\
\hline & C-terminus & CAG1 & ACC CTAGTC GGT AAT GGG TTA & -856 & 50 & (Sicinschi et al., 2010) \\
\hline & & CAG2 & GTA ATT GTC TAG TTT CGC & & & \\
\hline \multirow{2}{*}{\multicolumn{2}{|c|}{ babA2 }} & $B a b A 2 \mathrm{~F}$ & AATCCAAAAAGGAGAAAAAGTATGAAA & 852 & 55 & (Gerhard et al., 1999) \\
\hline & & $B a b A 2 \mathrm{R}$ & TGTTAGTGATTTCGGTGTAGGACA & & & \\
\hline
\end{tabular}


of $40 \mathrm{sec}$ at $94^{\circ} \mathrm{C}, 1 \mathrm{~min}$ at $55^{\circ} \mathrm{C}$ and $1 \mathrm{~min}$ at $72^{\circ} \mathrm{C}$. PCR products were visualized by electrophoresis in $1 \%$ agarose gel and examined under UV illumination. Primers used for PCR assays of $16 S r D N A$, cagA and babA2 genes are also listed in Table 1. As controls, amplified fragments of each gene from seven isolates were purified and sequenced with both forward and reverse primers by using BigDye technology on an ABI3700XL DNA sequencer (Applied Biosystems). The BLAST program (http://www.ncbi.nlm. nih.gov) was used to match the nucleotide sequences with the published sequences in GenBank.

\section{Data analysis}

Chi-square $\left(\chi^{2}\right)$ or Fisher's exact tests were used to assess the associations between the cagA and babA2 status and GC, whether independently or in combination. Patients with NAG were considered as controls. Odds ratios (ORs) and the corresponding 95\% confidence intervals (CIs) were also calculated. The Forward Stepwise LR (Likelihood Ratio) multiple logistic regression analysis was used for each gene individually, with adjustment for the potential confounders, including a threshold age of 40 years and sex. All the P-values were two-sided and $P<0.05$ was considered statistically significant. Data were collected and analyzed by using SPSS software (SPSS Science, Chicago, IL) version 19.0.

\section{Results}

\section{Patients characteristics}

The study population consisted of 103 patients, among theses, $56(54.37 \%)$ were diagnosed as gastritis and 47 (45.63\%) had suffered from GC. Occurrence of H.pylori infection was $80.58 \%(83 / 103)$. Among them, the results of $16 \mathrm{~S} r D N A$ PCR for $57.44 \%$ (27/47) of patients with GC and $100 \%(56 / 56)$ of those with NAG were positive. Generally, the total number of $83 \mathrm{H}$. pylori positive patients, $49(59 \%)$ males and $34(41 \%)$ females, with an average age of 48.7 years (the age range varied between

Table 2. Distribution of Study Patients According to Age and Sex

\begin{tabular}{lccccccc}
\hline & \multicolumn{3}{c}{ Age } & & \multicolumn{3}{c}{ Sex } \\
\cline { 2 - 4 } \cline { 3 - 4 } \cline { 8 - 9 } Disease & $<40$ & $>=40$ & Total & & Females & Males & Total \\
& $\mathrm{N}(\%)$ & $\mathrm{N}(\%)$ & & & $\mathrm{N}(\%)$ & $\mathrm{N}(\%)$ & \\
\hline \multirow{2}{*}{ NAG } & $17(31.5)$ & $37(68.5)$ & 54 & & $26(46.4)$ & $30(53.6)$ & 56 \\
GC & $1(4)$ & $24(96)$ & 25 & & $8(29.6)$ & $19(70.4)$ & 27 \\
Total & $18(22.8)$ & $61(77.2)$ & 79 & & $34(41)$ & $49(59)$ & 83 \\
\hline
\end{tabular}

Abbreviations: NAG, non-atrophic gastritis; GC, gastric cancer
20 and 90 years), were enrolled in the final analysis. In GC group, $70.4 \%(19 / 27)$ and $29.6 \%$ (8/27) were males and females, respectively. Characteristics of patients according to age and sex were shown in Table 2. Results of statistical analysis showed a significant association between age (OR $=11.027,95 \% \mathrm{CI}, 1.376-88.370 ; P=0.008)$, but not sex $(\mathrm{OR}=2.058,95 \% \mathrm{CI}, 0.773-5.878 ; P=0.162)$, and GC.

In this study, the prevalence of GC patients according to the anatomical site of the tumor origin was as follows: $53.19 \%$ (25/47) with gastric cardia cancer (GCC), $44.68 \%$ (21/47) with non-cardia GC (NCGC) and $2.13 \%(1 / 47)$ with both the GCC and the NCGC. Of the 47 GC patients, 27 were infected with $H$. pylori; of them $12(44.44 \%)$ were with GCC, 14 (51.85\%) with NCGC and $1(3.70 \%)$ with both the GCC and the NCGC. The prevalence of the intestinal- and the diffuse-type of adenocarcinoma and the squamous-cell carcinoma and the mucinous carcinoma of the stomach was $65.22 \%$ (30/46), $30.43 \%$ (14/46), $2.17 \%$ (1/46) and $2.17 \%(1 / 46)$, respectively. This information was not available for one patients. Among of $H$. pylori infected patients, $53.85 \%(14 / 26)$ and $46.15 \%(12 / 26)$ had the intestinal- and the diffuse-type of adenocarcinoma, respectively. None of the patients had a mixed type of adenocarcinoma.

\section{Genotyping of cagA and babA2}

The distribution of the $c a g A$ or $b a b A 2$ positive and negative strains in patients was shown in Table 3 . The $c a g A$ and $b a b A 2$ genes were detected in $50.6 \%(42 / 83)$ and $26.5 \%(22 / 83)$ of $H$. pylori strains. In this study, the total prevalence of the cagA-, babA2-, cagA+/babA2+, cagA-/babA2+, cagA+/babA2- and cagA-/babA2were as follows: $49.4 \%(41 / 83), 73.5 \%(61 / 83), 19.3 \%$ (16/83), 7.2\% (6/83), $31.3 \%$ (26/83) and $42.2 \%(35 / 83)$, respectively. The prevalence of the $c a g A+$ and $b a b A 2-$ strains was higher than $c a g A-$ and $b a b A 2+$ strains. In our study, strains carrying the $c a g A$ and $b a b A 2$ genes were also more frequent in GC patients $(55.6 \%$ and $40.7 \%$, respectively) than in the control group (NAG) (48.2\% and $19.6 \%$, respectively). However, no significant association was found between the cagA+ strains and the risk of GC ( $\mathrm{P}>0.05)$. Although, the prevalence of the $c a g A+/ b a b A 2+$ and cagA-lbabA2+ genotype combinations in patients with GC (25.9\% and $14.8 \%$, respectively) was higher than in those with NAG (16.1\% and $3.6 \%$, respectively), no significant association with GC was found. Furthermore, the cagA+/babA2 - and cagA-/babA2- genotype combinations did not show any significant association with $\mathrm{GC}(\mathrm{P}>0.05)$. The presence of the $b a b A 2$ gene significantly

Table 3. Association between the $H$. pylori cagA and babA2 Genes and GC Risk

\begin{tabular}{lrrrr}
\hline Genotypes & NAGN $(\%)$ & GCN $(\%)$ & TotalN $(\%)$ & OR (95\% CI) \\
\hline cagA+ & $27(48.2)$ & $15(55.6)$ & $42(50.6)$ & $1.343(0.435-3.773)$ \\
cagA- & $29(51.8)$ & $12(44.4)$ & $41(49.4)$ & 0.531 \\
babA2+ & $11(19.6)$ & $11(40.7)$ & $22(26.5)$ & $2.813(1.022-7.737)$ \\
babA2- & $45(80.4)$ & $16(59.3)$ & $61(73.5)$ & 0.041 \\
cagA+/babA2+ & $9(16.1)$ & $7(25.9)$ & $16(19.3)$ & $1.828(0.895-5.985)$ \\
cagA-lbabA2+ & $2(3.6)$ & $4(14.8)$ & $6(7.2)$ & $4.696(0.803-27.461)$ \\
cagA+/babA2- & $18(32.1)$ & $8(29.6)$ & $26(31.3)$ & $0.889(0.328-2.412)$ \\
cagA-lbabA2- & $27(48.2)$ & $8(29.6)$ & $35(42.2)$ & $0.452(0.170-1.203)$ \\
\hline
\end{tabular}

Abbreviations: NAG, non-atrophic gastritis; GC, gastric cancer; OR, odds ratio; CI, confidence interval 
increased the risk of $\mathrm{GC}$ in the multiple logistic regression with adjustment for age and sex $(\mathrm{OR}=5.068,95 \% \mathrm{CI}$, 1.506-17.058; $P=0.009)$.

\section{Discussion}

Ardabil, a Northwestern province of Iran, is one of the areas with the highest GC incidence rate in the world. In the present study, we therefore investigated the association of the $c a g A$ and $b a b A 2$ status with the risk of GC in Ardabil population. Through analyzing the data by means of logistic regression, the results showed no significant association between the $\operatorname{cagA}$ status of H. pylori and GC risk; however, the importance of CagA EPIYA polymorphisms has not been confirmed in Ardabil population yet; therefore, determining the associations of the $\operatorname{CagA}$ EPIYA polymorphisms with $\mathrm{GC}$ is important in this high-risk area. Recent studies have shown that the multiple repeats of $H$. pylori CagA EPIYA-C phosphorylation sites predict risk of gastric ulcer (GU) in Iran (Honarmand-Jahromy et al., 2015). The GU and GC have etiologic factors in common, which are likely to be caused by the $H$. pylori-induced atrophic gastritis (Hansson et al., 1996). We found that the cagA gene is highly prevalent in Ardabil patients (50.6\%), but it could not be considered as an important risk factor for GC. However, in agreement with other studies (Dabiri et al., 2009; Joober et al., 2012), a high frequency of the cagA gene was also observed in GC patients in our study (55.6\%). Several studies on Tehran population, of Iran, indicated no significant association between the presence of the cagA gene and GC risk (Jafari et al., 2008; Dabrii et al., 2010; Bagheri et al., 2013). In contrast, study conducted by Cittelly et al. in Colombians showed that the frequency of the $\operatorname{cagA}$ gene was significantly higher in GC patients $(80 \%)$ than in control groups $(51.4 \%)$ $(\mathrm{P}<0.01)$. They proposed that the presence of the cagA gene significantly increased the risk of GC (Cittelly et al., 2002). Also, study performed by Cavalcant et al. from a high-risk area of GC in Brazil demonstrated that the presence of the $\operatorname{cag} A$ gene particularly associated with the risk of $\mathrm{GC}(\mathrm{OR}=10.36)$ (Cavalcante et al., 2012). A recent follow-up study from a high-risk area of GC in Spain showed that infection with $\mathrm{cag} A+/ \mathrm{vacAs} 1 / \mathrm{m} 1$ strains was related to the progression of gastric precancerous lesions $(\mathrm{OR}=4.80)$ compared with those infected with strains that harbored the cagA-/vacAs2/m2 genotype (González et al., 2011). In other study which was performed in a low-risk area of Okinawa of Japan, a strong relationship was found between $\mathrm{cag} A$ gene and GC risk in comparison with control groups, in a multiple logistic regression (OR = 6.68) (Matsunari et al., 2012). The prevalence of the cagA gene in Western and Eastern countries was reported to be $60 \%$ and $95 \%$, respectively, however, only in Western countries, a significant association with GC was found (Kim et al., 2001; González et al., 2011). A meta-analysis conducted by Zhao et al. also showed that the H. pylori CagA antibody of the serum could not be useful for detecting GC in East Asian countries, with the highest incidence rates of GC (Zhao et al., 2014). This is in agreement with the results of the present study which was conducted in a genotype level and restricted to Ardabil, with the highest GC incidence rate in Iran and different ethnic group characteristics, Azeri with an Altaic language family. Interestingly, it has also been shown that the H. pylori CagA-negative non-virulent isolates may be a potential risk factor of pancreatic cancer (Chen et al., 2015).

Our findings demonstrated that the prevalence of the subjects harboring $b a b A 2-$ strains was significantly higher than the subjects with $b a b A 2+$ strains. The babA2+ $\mathrm{H}$ pylori isolates were present in approximately $26.5 \%$ of the study population. The patients infected with the $H$. pylori strains which carry babA2 gene showed a higher risk of developing GC which was about 5.068 fold, by the multiple logistic regression; therefore, it could be considered an important virulence factor in Ardabil population. We have previously shown no significant difference in the distribution of the $b a b A 2$ and $c a g A$ genes among $H$. pylori isolates from high $(34.2 \%$ and $75.6 \%$, respectively) and low (44.4\% and $63.9 \%$, respectively) incidence GC areas ( $\mathrm{P}>0.05)$ (Latifi-Navid et al., 2013). In Iran, the frequency of $b a b A 2$ genotype was $40.6 \%$ (Abadi et al., 2013; Latifi-Navid et al., 2013), which was strongly associated with GC in comparison with the control groups $(P=0.0004)$ (Abadi et al., 2013). Similarly, study conducted by Gerhard et al. showed that frequency of the babA2 gene in GC patients (78\%) was higher than those with gastritis $(51 \%)$, with significant difference (Gerhard et al., 1999). Erzin et al. showed that the frequency of the $b a b A 2$ gene in GC patients $(87.9 \%)$ was higher than those with NAG $(23.3 \%)(P=0)$ (Erzin et al., 2006). Furthermore, in Germany, Turkey, or northern Portugal, $b a b A 2$ expression was closely associated with the severity of gastrointestinal disease (Gerhard et al., 1999; Azevedo et al., 2008; Erzin et al., 2008), while in Portuguese and Thai populations, the presence of the babA2 gene was not associated with GC risk (Gatti et al., 2006; Chomvarin et al., 2008). These results reflect the fact that the associations of $H$. pylori virulence genes/ alleles with GC risk have been widely varied according to geographic variation/ or ethnic origin.

We proposed that the $H$. pylori babA2 positivity might be considered as an important determinant of GC risk in Ardabil. Hence, this study provided us with valuable information which might be helpful to reduce the incidence of GC in high-risk areas, particularly Ardabil. We propose that more investigations with a sufficient number of samples are necessary in order to better depicting the bacterial genotype diversity and the role of environmental and host factors and their associations with $\mathrm{GC}$ in this the very high-incidence area.

\section{Acknowledgements}

This study was supported by the Research Council of the University of Mohaghegh Ardabili grant P/T 207. The supporter had no role in study design, data collection and analysis, decision to publish, or preparation of the manuscript. The authors have declared that no competing interests exist. 


\section{References}

Abadi ATB, Taghvaei T, Mobarez AM, et al (2013). High correlation of babA2-positive strains of Helicobacter pylori with the presence of gastric cancer. Internal and Emergency Med, 8, 497-501.

Abasiyanik MF, Sander E, Salih BA (2002). Helicobacter pylori anti-CagA antibodies: prevalence in symptomatic and asymptomatic subjects in Turkey. Canadian journal of gastroenterology= Journal canadien de gastroenterologie, 16, 527-32.

Alireza S, Mehdi N, Ali M, et al (2005a). Cancer occurrence in Iran in 2002, an international perspective. Asian Pac J Cancer Prev, 6, 359-63.

Alireza S, Mehdi N, Ali M, et al (2005b). Cancer occurrence in Iran in 2002, an international perspective. Asian Pac J Cancer Prev, 6, 359.

Argent RH, Hale JL, El-Omar EM, et al (2008). Differences in Helicobacter pylori CagA tyrosine phosphorylation motif patterns between western and East Asian strains, and influences on interleukin-8 secretion. J Med Microbiol, 57, 1062-7.

Azevedo M, Eriksson S, Mendes N, et al (2008). Infection by Helicobacter pylori expressing the BabA adhesin is influenced by the secretor phenotype. J Pathol, 215, 308-16.

Babaei M, Jaafarzadeh H, Sadjadi A, et al (2009). Cancer incidence and mortality in Ardabil: Report of an ongoing population-based cancer registry in Iran, 2004-2006. Iranian Journal of Public Health, 38, 35-45.

Babaei M, Pourfarzi F, Yazdanbod A, et al (2010). Gastric cancer in Ardabil, Iran--a review and update on cancer registry data. Asian Pac J Cancer Prev, 11, 595-9.

Bagheri N, Taghikhani A, Rahimian G, et al (2013). Association between virulence factors of Helicobacter pylori and gastric mucosal interleukin-18 mRNA expression in dyspeptic patients. Microbial pathogenesis, 65, 7-13.

Bakhti SZ, Latifi-Navid S, Mohammadi S, et al (2015). Relevance of Helicobacter pylori vacA 3-end Region Polymorphism to Gastric Cancer. Helicobacter.

Basso D, Zambon CF, Letley DP, et al (2008). Clinical relevance of Helicobacter pylori cagA and vacA gene polymorphisms. Gastroenterology, 135, 91-9.

Cavalcante MQdF, Silva CIS, Braga-Neto MB, et al (2012). Helicobacter pylori vacA and cagA genotypes in patients from northeastern Brazil with upper gastrointestinal diseases. Memórias do Instituto Oswaldo Cruz, 107, 561-3.

Chang WL, Yang HB, Cheng HC, et al (2015). Intracellular Osteopontin Induced by CagA-positive Helicobacter pylori Promotes Beta-catenin accumulation and interleukin-8 secretion in gastric epithelial cells. Helicobacter.

Chen XZ, Wang R, Chen HN, et al (2015). Cytotoxin-Associated Gene A-Negative Strains of Helicobacter pylori as a Potential Risk Factor of Pancreatic Cancer: A meta-analysis based on nested case-control studies. Pancreas, 44, 1340-4.

Chomvarin C, Namwat W, Chaicumpar K, et al (2008). Prevalence of Helicobacter pylori vacA, cagA, cagE, iceA and $b a b A 2$ genotypes in Thai dyspeptic patients. Int J Infect Dis, 12, 30-6.

Cittelly D, Huertas M, Martinez J, et al (2002). [Helicobacter pylori genotypes in non atrophic gastritis are different of the found in peptic ulcer, premalignant lesions and gastric cancer in Colombia]. Revista medica de Chile, 130, 143-51.

Dabiri H, Maleknejad P, Yamaoka Y, et al (2009). Distribution of Helicobacter pylori cagA, cagE, oipA and vacA in different major ethnic groups in Tehran, Iran. Journal of gastroenterology and hepatology, 24, 1380-6.

Dabrii H, Bolfion M, Mirsalehian A, et al (2010). Analysis of Helicobacter pylori genotypes in Afghani and Iranian isolates. Polish journal of microbiology/Polskie Towarzystwo Mikrobiologow $=$ The Polish Society of Microbiologists, 59, 61-6.

Derakhshan M, Yazdanbod A, Sadjadi A, et al (2004). High incidence of adenocarcinoma arising from the right side of the gastric cardia in NW Iran. Gut, 53, 1262-6.

Dixon MF, Genta RM, Yardley JH, et al (1996). Classification and grading of gastritis: the updated Sydney system. The American journal of surgical pathology, 20, 1161-81.

Erzin Y, Koksal V, Altun S, et al (2006). Prevalence of Helicobacter pylori vacA, cagA, cagE, iceA, babA2 genotypes and correlation with clinical outcome in Turkish patients with dyspepsia. Helicobacter, 11, 574-80.

Erzin Y, Koksal V, Altun S, et al (2008). Role of host interleukin 1 beta gene (IL-1B) and interleukin 1 receptor antagonist gene (IL-1RN) polymorphisms in clinical outcomes in Helicobacter pylori-positive Turkish patients with dyspepsia. J Gastroenterol, 43, 705-10.

Ferlay J, Soerjomataram I, Dikshit R, et al (2015). Cancer incidence and mortality worldwide: sources, methods and major patterns in GLOBOCAN 2012. Int J Cancer, 136, 359-86.

Ferreira RM, Pinto-Ribeiro I, Wen X, et al (2015). Helicobacter pylori cagA promoter region sequences influence $C a g A$ Expression and Interleukin 8 Secretion. J Infect Dis.

Figueiredo C, Machado JC, Pharoah P, et al (2002). Helicobacter pylori and interleukin 1 genotyping: an opportunity to identify high-risk individuals for gastric carcinoma. $J$ Natl Cancer Inst, 94, 1680-7.

Gatti LL, Modena JL, Payao SL, et al (2006). Prevalence of Helicobacter pylori cagA, iceA and babA2 alleles in Brazilian patients with upper gastrointestinal diseases. Acta Trop, 100, 232-40.

Gerhard M, Lehn N, Neumayer N, et al (1999). Clinical relevance of the Helicobacter pylori gene for blood-group antigenbinding adhesin. Proceedings of the National Academy of Sciences, 96, 12778-83.

González CA, Figueiredo C, Lic CB, et al (2011). Helicobacter pylori cagA and vacA genotypes as predictors of progression of gastric preneoplastic lesions: a long-term follow-up in a high-risk area in Spain. The American J Gastroenterol, 106, 867-74.

Hansson LE, Nyren O, Hsing AW, et al (1996). The risk of stomach cancer in patients with gastric or duodenal ulcer disease. $N$ Engl J Med, 335, 242-9.

Honarmand-Jahromy S, Siavoshi F, Malekzadeh R, et al (2015). Multiple repeats of Helicobacter pylori CagA EPIYA-C phosphorylation sites predict risk of gastric ulcer in Iran. Microb Pathog, 89, 87-92.

Ilver D, Arnqvist A, Ögren J, et al (1998). Helicobacter pylori adhesin binding fucosylated histo-blood group antigens revealed by retagging. Science, 279, 373-7.

Jafari F, Shokrzadeh L, Dabiri H, et al (2008). vacA genotypes of Helicobacter pylori in relation to cagA status and clinical outcomes in Iranian populations. Japanese journal of infectious diseases, 61,290-3.

Joober R, Schmitz N, Annable L, et al (2012). Publication bias: What are the challenges and can they be overcome? Journal of psychiatry \& neuroscience: JPN, 37, 149-52.

Kim SY, Woo CW, Lee YM, et al (2001). Genotyping CagA, VacA subtype, IceA1, and BabA of Helicobacter pylori isolates from Korean patients, and their association with gastroduodenal diseases. Journal of Korean medical science, 16, 579-84.

Latifi-Navid S, Ghorashi SA, Siavoshi F, et al (2010). Ethnic and geographic differentiation of Helicobacter pylori within 
Latifi-Navid S, Mohammadi S, Maleki P, et al (2013). Helicobacter pylori vacA d1/-i1 genotypes and geographic differentiation between high and low incidence areas of gastric cancer in Iran. Archives of Iranian Med, 16, 330-7.

Lee H, Choe G, Kim W, et al (2006). Expression of Lewis antigens and their precursors in gastric mucosa: relationship with Helicobacter pylori infection and gastric carcinogenesis. The J Pathol, 209, 88-94.

Leung WK, Chan MC, To K-F, et al (2006). H. pylori genotypes and cytokine gene polymorphisms influence the development of gastric intestinal metaplasia in a Chinese population. The American J Gastroenterol, 101, 714-20.

Lu Y, Redlinger TE, Avitia R, et al (2002). Isolation and genotyping of Helicobacter pylori from untreated municipal wastewater. Applied and Environmental Microbiol, 68, 1436-9.

Malekzadeh R, Sotoudeh M, Derakhshan M, et al (2004). Prevalence of gastric precancerous lesions in Ardabil, a high incidence province for gastric adenocarcinoma in the northwest of Iran. J Clinical Pathol, 57, 37-42.

Matsunari O, Shiota S, Suzuki R, et al (2012). Association between Helicobacter pylori virulence factors and gastroduodenal diseases in Okinawa, Japan. J Clinical Microbiol, 50, 876-83.

Mattar R, Marques SB, do Socorro Monteiro M, et al (2007). Helicobacter pylori cag pathogenicity island genes: clinical relevance for peptic ulcer disease development in Brazil. Journal of medical microbiology, 56, 9-14.

Nouraie M, Latifi-Navid S, Rezvan H, et al (2009). Childhood hygienic practice and family education status determine the prevalence of Helicobacter pylori infection in Iran. Helicobacter, 14, 40-6.

Ohnishi N, Yuasa H, Tanaka S, et al (2008). Transgenic expression of Helicobacter pylori CagA induces gastrointestinal and hematopoietic neoplasms in mouse. Proceedings of the National Academy of Sciences, 105, 1003-8.

Peek RM, Jr., Fiske C, Wilson KT (2010). Role of innate immunity in Helicobacter pylori-induced gastric malignancy. Physiol Rev, 90, 831-58.

Raei N, Latifi-Navid S, Zahri S (2015). Helicobacter pylori cag Pathogenicity Island $c a g L$ and $\operatorname{orf} 17$ Genotypes predict risk of peptic ulcerations but not gastric cancer in Iran. Asian Pac J Cancer Prev, 16, 6645-50.

Sadjadi A, Malekzadeh R, Derakhshan MH, et al (2003). Cancer occurrence in Ardabil: Results of a population-based Cancer Registry from Iran. Intern J Cancer, 107, 113-8.

Sicinschi L, Correa P, Peek R, et al (2010). CagA C-terminal variations in Helicobacter pylori strains from Colombian patients with gastric precancerous lesions. Clinical Microbiology and Infection, 16, 369-78.

Sozzi M, Tomasini ML, Vindigni C, et al (2005). Heterogeneity of cag genotypes and clinical outcome of Helicobacter pylori infection. J Laboratory Clin Med, 146, 262-70.

Suerbaum S, Michetti P (2002). Helicobacter pylori infection. New England J Med, 347, 1175-86.

Tan HJ, Rizal AM, Rosmadi MY, et al (2006). Role of Helicobacter pylori virulence factor and genotypes in nonulcer dyspepsia. J gastroenterol hepatol, 21, 110-5.

Yong X, Tang B, Li BS, et al (2015). Helicobacter pylori virulence factor $\mathrm{CagA}$ promotes tumorigenesis of gastric cancer via multiple signaling pathways. Cell Commun Signal, 13, 30.

Zhao Z, Li Y, Liu S, et al (2014). Serum Helicobacter pylori CagA antibody may not be used as a tumor marker for diagnosing gastric cancer in east Asian countries. Tumour Biol, 35, 12217-24. 